DOI: http://doi.org/10.4038/jbs.v3i1.33

\title{
THE IMPACT OF POWER, BENEFITS, AND RISK REDUCTION ON THE PERFORMANCE OF SUPPLY CHAIN OF SRI LANKAN APPAREL AND FOOD \& BEVERAGES INDUSTRIES
}

\author{
Harsha Prabashini Gallage and Dileepa M. Endagamage \\ Department of Decision Sciences, Faculty of Management Studies and Commerce \\ University of Sri Jayewardenepura \\ harshagallage@ymail.com, dileepaendagamage@sjp.ac.lk
}

\begin{abstract}
Supply chain performance (SCP) can be determined through many factors such as technical factors and relationship factors. The relationship factors mainly focus on the supply chain linkages (SCLs) created with the upstream and downstream supply chain partners. Therefore, the SCLs such as Power, Benefits, and Risk Reduction are important to any industry to enhance their SCP. This paper examines the level of impact of the Power, Benefits, and Risk Reduction on the SCP. The SCLs and the SCP are analyzed and compared using two types of industries as Apparel (AI), and Food \& Beverages (F\&BI) that established in Free Trade Zones in Western Province Sri Lanka. A total of 138 Managers in the fields of Supply Chain (SC) related activities were surveyed (88-AI, 50- F\&BI) through a self-administrative questionnaire. Risk Reduction and Power together demonstrate a significant influence on the SCP in manufacturing sector in Sri Lanka. Further, 'Industry type' moderates the relationships of Power to SCP and Risk Reduction to SCP but not the Benefits to SCP. In F\&BI, the Power, Benefits, and Risk Reduction demonstrate significant (5\% level) relationships with SCP but, the Power is not showing significant (5\% level) relationship with SCP in AI. In F\&BI, Risk Reduction and Benefits together demonstrate significant influence on SCP. But in AI, Benefits with the Power demonstrate significant influence on SCP. AI shows higher level of SCP than the F\&BI, when the same level of Power and Risk Reduction apply to their own Supply Chain.
\end{abstract}

Key Words: Supply chain performance, Supply chain management, Supply chain linkages 


\section{INTRODUCTION}

Increase the effectiveness of an organization is an important point to be addressed. In today`s world, Supply Chain Management (SCM) can be identified as one of the main strategies used to improve effectiveness of manufacturing and service organizations. Lee, Kwon, and Severance (2007) mentioned SCM as an integrated management tool used to enhance the quality, lower the cost, and satisfy the ultimate customer. SCM helps information, materials, and services to flow effectively, through different facilities to the stakeholders of the organization. Proliferation in product lines, shorter product life cycles, higher level of outsourcing, shift in power structure in the chain, and globalization of manufacturing are trends that made SCM a critical success factor in most industries (shah, 2009, p. 1012).

Further, to enhance the effectiveness of an organization, the authorities pay attention on better realization of organizational goals, such as, enhanced competitiveness, better customer care and increase profitability of the organization (Gunasekaran, Patel, \& Tirtiroglu, 2001).

Several studies discuss Supply Chain Performances (SCP) as a measure related to competitiveness, customer care, and profitability of the organization. Having ultimate customer satisfaction as an indicator, initially large number of scholars measure the SCP based on technological factors such as, explaining Enterprise Resource Planning systems (Zong, 2008), Radio frequency identification (Lee, Cheng, \& Leung, 2009) and etc.

measure the SCP based on technological factors such as, explaining Enterprise Resource Planning systems (Zong, 2008), Radio frequency identification (Lee, Cheng, \& Leung, 2009) and etc.

In today's era, it is not only the technological integrations that improve the efficiency and effectiveness of a Supply Chain, but rather the integrated long term relationships with the members of Supply Chain play a critical role in handling Supply chain performance (Lee et al., 2007; Singh \& Power, 2009; Whitten, Green, \& Zelbst, 2012; Zelbst, Green, Sower, \& Reyes, 2009).

Supply chain performance (SCP) can be determined through many factors such as, technical factors and relationship factors. The relationship factors mainly focus on the Supply chain linkages (SCLs) created with the upstream and downstream Supply Chain partners. The SCP can also be varied due to the social exchange context by way of exchanging the relationships prevailing amongst Supply Chain network partners.

Therefore, the current study mainly pay attention on the Supply Chain Linkage (SCL) build on Power, Benefits and Risk Reduction as the ways of exchange relationships (Zelbst et al., 2009). Singh and 
Power (2009), described that the collaboration with customers is more directly related to the performance outcomes measured. Therefore, the performance measurement of this study defined as the ability to satisfy ultimate customer, in terms of both quality and cost (Zelbst et al., 2009). ability to satisfy ultimate customer, in terms of both quality and cost (Zelbst et al., 2009).

\section{BACKGROUND}

To control the inventory by managing the flow of materials will be the primary purpose of the Supply Chain design. In general, a manufacturer spends more than $60 \%$ of his total earnings to purchase services and materials necessary for his industry (Krajewski, Ritzman, Malhotra, \& Srivastav, 2011, p. 326).

"Supply chain linkages" of an organization refers to explicit and/or implicit connections with the Supply Chain critical entities of the organization. These relationships can comprise of power to manage the flow and quality of the inputs received from suppliers and the outputs received to the customers (Rungtusanatham, Salvador, Forza, \& Choi, 2003). There are few noteworthy case studies that highlight the importance of the relationship between the organization and the suppliers and customers (Singh \& Power, 2009). The case studies of high profile organizations such as Dell (Magretta, 1998) and HP (Lee \& Billington, 1995) highlight the importance of having close collaborative arrangements with their trading partners.
Okongwu, Brulhart, and Moncef (2015) explained, SCLs as information sharing, supplier partnership and customer relationship. Rungtusanatham et al. (2003) mentioned SCLs as a resource and as a resource acquisition capability. Lee et al. (2007) analysed the SCLs of supplier, internal integration, and customer with SCP of the organization.

(2007) analysed the SCLs of supplier, internal integration, and customer with SCP of the organization.

Well-defined SCL is a key determinant to improve the SCP and reliability across a wide range of industries (Lee et al., 2007). Therefore, the SCL and the SCP can be defined as an interrelated connection.

Gunasekaran et al. (2001) studied that the performance measurements not only consider the cost of activities, but also its impact on other functions such as, customer service, asset utilization, productivity and quality. Therefore, SCLs will improve the Supply Chain efficiency and effectiveness. Ultimately, the customer will be satisfied with the reduced cost and improved quality.

This study will expose the Supply chain linkages based on social factors such as, Power (Burke, 1997; Cook \& Whitmeyer, 1992), Benefits (Rungtusanatham et al., 2003; Zelbst et al., 2009) and Risk Reduction (Cucchiella \& Gastaldi, 2006; Vilko, Rital, \& Edelmann, 2014). Further, 
this discusses the impact of the said linkage factors on the SCP which leads to satisfy the ultimate customer.

\section{RESEARCH PROBLEM}

The Free Trade Zones (FTZ) which is managed by the Board of Investments, Sri Lanka, (BOI) have excellent level of infrastructure facilities for foreign and local industries. Within these Zones (familiar as BOI Zones), the infrastructure facilities, tax benefits, labour accessibility, lodging facilities for employees, 24 hour Import/Export facilities, and security facilities are in excellent level. All the manufacturing organizations within these Zones enjoy the same benefits, the Annual Industry Survey, 2013 (AIS, 2013) highlights the differences of the performance in different industries.

According to Lee et al. (2007) and Selldin and Olhager (2007), nature of the industry can be a significant factor for different levels of performance of SC. Is it the only reason to vary the SCP of manufacturing organizations in BOI Zones? It can be suspected that there can be various factors affecting on SCP other than these facilities and industry type.

SCP can be high or low due to the behaviours of technical activities and social activities of the organization (Lee et al., 2007; Singh \& Power, 2009; Whitten et al., 2012; Zong, 2008). Therefore, the current study will pay its attention on how the SCLs influence to change of the SCP of an organization.

\section{OBJECTIVES OF THE STUDY}

The main objective of this study is to assess the extent to which the SCLs such as Power, Benefits, and Risk Reduction will predict the $\mathrm{SCP}$ of manufacturing organizations in BOI Zones in Sri Lanka. Further, it discusses the relationship between the said SCLs and the SCP, moderating effect of the type of the industry, and a comparison of the ratings given by the Managers for the SCLs and the SCP of their own organization. industry, and a comparison of the ratings given by the Managers for the SCLs and the SCP of their own organization.

\section{LITERATURE REVIEW}

This section discuss about a Supply Chain, Supply Chain Linkages, and the Supply Chain Performance respectively. Supply Chain Linkages discuss under three categories i.e. Power, Benefits and Risk reduction.

\subsection{A Supply Chain}

A Supply Chain comprises all the activities associated with the flow and transformation of goods from the raw materials stage, through to the end user, as well as the associated information flows (Handfield \& Nichols, 2002, p. 8). Further, cooperative organizational relationships that provide high value for the integrated parties are essential for an effectiveness of a Supply Chain. The disadvantages such as, high operational costs, inefficiency, and demand 
uncertainty of a Supply Chain can be reduced by having strong long term alliances with Supply Chain partners (Fawcett, Magnan, and McCarter, 2008).

Build trust and high degree of mutual obligation between exchange parties would be beneficial for organisational relationships (Gakovic \& Tetrick, 2003; Shore, Bommer, Rao, \& Seo, 2009; Wang, Tsui, Zhang, \& Ma, 2003; Zineldin \& Jonsson, 2000).

The Social Exchange theory explains, the "behaviour (profit)" of any person /organization is as the difference of the "rewards of interaction" and the "cost of interaction" (Cropanzano \& Mitchell, 2005). It is also mentioned that the resource exchange and social exchange are interrelated. (Cook \& Whitmeyer, 1992; Olkkonen, Tikkanen, \& Alajoutsijarvi, 2000; Pels, 1999). These interrelated relationships or networks build among individual(s) or corporate actors such as, buyers and suppliers (Markovsky, Skvoretz, Willer, Lovaglia, \& Erger, 1993; Zelbst et al., 2009).

"behaviour (profit)" of any person /organization is as the difference of the "rewards of interaction" and the "cost of interaction" (Cropanzano \& Mitchell, 2005). It is also mentioned that the resource exchange and social exchange are interrelated. (Cook \& Whitmeyer, 1992; Olkkonen, Tikkanen, \& Alajoutsijarvi, 2000; Pels, 1999). These interrelated relationships or networks build among individual(s) or corporate actors such as, Journal of Business Studies buyers and suppliers (Markovsky, Skvoretz, Willer, Lovaglia, \& Erger, 1993; Zelbst et al., 2009).

The ability to meet the demands made by an actor in a network creates closer relationship among suppliers and buyers (Anderson, Hakansson, \& Johanson, 1994; Awuah, 2001; Chandra \& Kumar, 2001; Sahay, 2003).

\subsection{Power}

Social exchange networks as discussed earlier, linked with the Power of the organization. Power is concerned as one's ability to influence on others (Farrell \& Schroder, 1999). The degree to which buyer can influence on the supplier depend on the power/dependency structure of the relationships. More powerful actors influence and control the behaviours and exchanges in buyer-supplier relationships (Habib, Bastl, \& Pilbeam, 2015; Hoejmose, Grosvold, \& Millington, 2013).

Hence, the Power can create negative or positive impact for the Supply chain performance (Awuah, 2001; Burke, 1997; Cook \& Whitmeyer, 1992; Walker et al., 2000; Zelbst et al., 2009). It is essential to understand the Power structures that exist in a Supply Chain strategically, and operationally manage the said Supply Chain (Cox, 1999; Hoejmose et al., 2013).

performance (Awuah, 2001; Burke, 1997; Cook \& Whitmeyer, 1992; Walker et al., 2000; Zelbst et al., 2009). It is essential to 
understand the Power structures that exist in a Supply Chain strategically, and operationally manage the said Supply Chain (Cox, 1999; Hoejmose et al., 2013).

The main point to understand is how to retain the Power and use it effectively to influence and control others in the Supply Chain (Cox, 1999; Sorensen, 2009).

\subsection{Benefits}

Benefits on the other hand, imply an exchange relationship based on gains or advantages (Cook \& Whitmeyer, 1992; Zelbst et al., 2009). The Supply Chain efficiency as a Benefit helps to reduce the existing and potential performance gaps (shah, 2009, p. 25). The opportunities to acquire knowledge by linking the organization to its suppliers or to the buyers can also be identified as a Benefit for the organization (Chua, 2003; Rungtusanatham etal., 2003).

According to Lin (2007), innovative ideas, processes, products or services are also be Benefits for an organization. Since the knowledge sharing and innovations facilitate to achieve desired outcomes, it is not unfair to treat them as Benefits to the organization (Hallen \& Johanson, 2004; Han \& Anantatmula, 2007; Jantunen, 2005; Lin, 2007, Neill \& Adya, 2007; Tohidinia \& Mosakhani, 2010).

Standardization, as a Benefit emphasize on advancement in transportation and communication technologies which facilitate the homogenization of consumer tastes and need patterns which positively influence the firm's performance (Donnell \& Jeong, 2000).

The current study pay attention on the knowledge sharing, innovations, efficiency and standards of the suppliers and the buyers as Benefits that influence on the SCP of the organization.

\subsection{Risk Reduction}

Zelbst et al. (2009) suggested that the scarcity of resources create a Risk, and organizations become members of a Supply Chain to reduce this Risk. The quality and the competitiveness of an organizations' operations depend on their ability to identify and mitigate the uncertainties and Risks they encounter (Matook, Lasch, \& Tamaschke, 2009; Vilko et al., 2014). Hence, the Reduction of Risk is another important linkage factor that influence on overall Supply Chain Performance.

Supply Chain risks can be divided in to two parts, based on its source such as, demander's risk and supplier's risk (Lockamy III \& McCormack, 2012). Demander's risk will be resulting from the disruptions emerging from the downstream Supply Chain. Supplier's side risks are the disruptions occurred from the upstream Supply Chain include the purchasing, supplier activities, and supplier relationships.

supplier activities, and supplier relationships. 
There can be non financial consequences, which leads to a Risk. Supply Chain disruptions, such as, reduction in product quality, damages to property, lost reputation among the Supply Chain partners, and delivery delays (Cousins, Lamming, \& Bowen, 2004) can be some of those.

Perry and Sohal (2001) and Salvador, Forza, Rungtusanatham, and Choi (2001) discussed facts related to timely performance with the intention of reducing the risk of occurrence of delays and improve the Supply Chain Performance.

\subsection{Supply Chain Performance}

Well integrated Supply Chain is one of the primary business strategies that apply to improve the SCP of the organization. The ability of Supply Chain partners to focus on ultimate customer and to respond the changes in demand, will lead for a better SCP (Whitten et al., 2012).

Beamon (1999) and Singh and Power (2009) expressed that the strong, deep, meaningful and long term engagements with buyers and suppliers produce performance improvements. Such effective and efficient Supply Chain integration will ultimately satisfy the customer (buyer), both in terms of low price and high quality.

Hence, most of the studies in SCM measured the SCP by measuring each linkage based on the ability to satisfy the ultimate customer
(Lee et al., 2007; Zelbst et al., 2009).

the ability to satisfy the ultimate customer (Lee et al., 2007; Zelbst et al., 2009).

\section{METHODOLOGY}

\subsection{Conceptual framework}

According to the figure 6.1, the conceptual framework of the study has developed based on the literature related to SCP, SCLs and SCM. Power (Burke, 1997; Cook \& Whitmeyer, 1992; Walker et al., 2000; Zelbst et al., 2009), Benefits (Han \& Anantatmula, 2007; Tohidinia \& Mosakhani, 2010) and Risk Reduction (Cucchiella \& Gastaldi, 2006; Matook et al., 2009; Vilko et al., 2014) were the SCLs considered in this study.

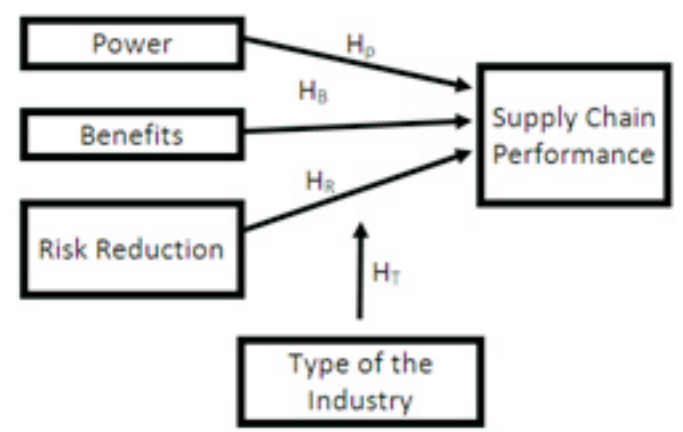

Figure 6.1: Conceptual framework Source: Survey data

SCP depends on various factors, including these SCLs (Gunasekaran et al., 2001; Lee et al., 2007; Singh \& Power, 2009; Whitten et al., 2012; Zelbst et al., 2009). The SCP can be varied as well, due to the type of the product (or the industry) (Selldin \& Olhager, 2007). The current study, is similar to the 
study done by Zelbst et al. (2009), but the industry types and the study design is different. This study focus on the impact of Power, Benefits, and Risk Reduction (independent variables), on the Supply chain performance (dependent variable) of an organization.

industry types and the study design is different. This study focus on the impact of Power, Benefits, and Risk Reduction (independent variables), on the Supply chain performance (dependent variable) of an organization.

\subsection{Hypotheses of the study}

There are four main hypotheses tested with the collected data. Three of them used to test the significance of the three relationships between SC linkages and the SCP. Fourth hypothesis $\mathrm{H}_{\mathrm{T}}$, tested the moderating effect of the "type of the industry".

$\mathrm{H}_{\mathrm{p}}$ : Higher the ability to control the activities of suppliers, buyers, and competitors, the SCP of the organization will be higher.

$\mathrm{H}_{\mathrm{B}}$ : Higher the level of receiving/ giving Benefits from/ to the suppliers and the buyers, the SCP of the organization will be higher.

$\mathrm{H}_{\mathrm{R}}$ : Higher the ability to control the Risks, the Supply chain performance will be higher. $\mathrm{H}_{\mathrm{T}}$ : The type of the industry moderates the relationship of SC linkages to SCP of the organization.

\subsection{Population and the Sample}

The target population of the study is the Apparel Industry (AI) and Food \&
Beverages Industry (F\&BI) in BOI Zones in Western Province, Sri Lanka. BOI Zones facilitated with the boarding facilities for the labourers and the companies can obtain tax grant while performing their operations within the BOI Zones.

There are seven BOI Zones within the Western Province. The largest two Zones in Sri Lanka named Katunayaka and Biyagama are also located in the Western Province. Therefore the selected area for the study is the Western Province BOI Zones. The Area Sampling technique which helps to limit the geographical area of a survey was used to define the area of the current survey. This helps to ensure the quality of the data gathered with the limited time and resources. Out of the seven Zones in the Western Province, four Zones named Katunayaka, Biyagama, Wathupitiwala and Horana were selected at random. The organizations within the Zones were also selected at random. These Zones are facilitated with same infrastructure facilities even though the different organisations located there demonstrate different performances (AIS, 2013). Respondents are the senior level Managers who are working for the selected organizations and are involved in the fields of operations, supply chain, logistics, procurement, warehouse, materials management, production and transportation. The sample consists of 88 managerial employees from the AI and 50 managerial employees from the F\&BI within the selected BOI Zones. 


\subsection{Design of the study}

The current study designed as a cross sectional sample survey. Data collection was carried out by using self-administrative questionnaire that were given to the Senior Managers of the selected organizations.

\subsection{Data Collection and the Tool}

The questionnaire consists of the items related to the four concepts of the study, such as, Power, Benefits, Risk Reduction and SCP. Power, Benefits, and Risk Reduction measurement scales were developed based on the studies of Cook and Whitmeyer (1992); Lee et al. (2007); Tohidinia and Mosakhani (2010); Vilko et al. (2014); Walker et al. (2000); Zelbst et al. (2009). The existing measurement scales were amended appropriately to present a better clarification for the items in the questionnaire.

The questionnaire comprises of two parts. The first part includes the demographic data and few organizational statistics, like number of employees, suppliers, and monthly output in units.

Second part of the questionnaire focuses on the existing level of SCL and the organizational Supply chain performance. Five point Likert scale had been used to identify the level of agreement with the Supply chain linkage statements and the Supply chain performance. Respondents were informed to rate the items on five point scale ranging from 1(strongly disagree) to 5(strongly agree). Further, a sixth point (not applicable) is added to the scale to rate each of the items.
The measurement scales utilized for this study are; Power (4 items), Benefits (8 items), Risk reduction (8 items) and Supply chain performance (16 items). The total measurement scales (total items) are used to gather data in relation to the level of Supply chain linkages and the Supply chain performance.

gather data in relation to the level of Supply chain linkages and the Supply chain performance.

\subsection{Methods of Data Analysis}

The internal consistency and reliability of five point Likert scale measurements on level of Supply chain linkage and the Supply chain performance were measured using Cronbach`s Alpha coefficient.

The composition of the sample is outlined through the demographic factors; gender, age, job position, experience and the level of education. The statistics provide the basic idea of the characteristics of the population. The relationship between the SCL and the SCP are measured using the Spearman's correlation coefficient analysis.

Multiple linear regression analysis was used to identify the impact of the independent variables (Power, Benefits and Risk Reduction) on the SCP.

\section{ANALYSIS AND FINDINGS 7.1 Reliability and Validity}

Validity is the content to which an instrument (questionnaire/ survey/ test) measures, what it is supposed to measure and perform, as it is designed to perform. 
Validation involves collecting and analysing data to assess the accuracy of an instrument.

The measurement scales of this study were developed from the existing literature (Zelbst et al., 2009). Some of the measurement scales were revised and changed by considering the sample in order to furnish a clear understanding about what it is going to measure changed by considering the sample in order to furnish a clear understanding about what it is going to measure.

Reliability can be thought as internal consistency of a measuring tool. Internal consistency reliability means the consistency of results across items. Cronbach's Alpha coefficient is used to measure the internal consistency and the reliability of the items. The alpha values greater than or equal to 0.70 indicate a sufficient reliability (Gliem \& Gliem, 2003; Nunnally \& Bernstein, 1994, p. 265). The table 7.1 illustrates the Cronbach's Alpha values of the constructs used in this study. These values justify relatively high internal consistency of these constructs.

Table 7.1: Reliability Statistics

\begin{tabular}{lccc}
\hline \hline & P-Value & $\begin{array}{c}\text { Mean } \\
\text { of } \\
\text { F\&BI }\end{array}$ & $\begin{array}{c}\text { Mean } \\
\text { of } \\
\text { AI }\end{array}$ \\
Power & 0.305 & 4.189 & 3.994 \\
Benefits & $0.038^{*}$ & 4.133 & 3.912 \\
Risk R & 0.960 & 3.929 & 4.055 \\
SCP & $0.000^{* *}$ & 3.594 & 4.231 \\
\hline \hline
\end{tabular}

**. Significant at the 0.01 level.

*. Significant at the 0.05 level. Grouping Variable: Industry type Source: Survey data. Sample size $=138$
The study sample contains $64 \%$ of $\mathrm{AI}$ and $36 \%$ of F\&BI organizations. Out of the AI organizations, $72 \%$ comprise of a workforce of 101-500 and $21 \%$ are above 500 employees. All F\&BI organizations comprise a workforce of 101-500. All F\&BI organizations are handling 50 or less suppliers but nearly $18 \%$ AI organizations are handling more than 50 suppliers. Further there are nearly $10 \%$ AI organizations handling more than 150 suppliers which creates huge difficulty to maintain the quality and performances.

suppliers but nearly $18 \%$ AI organizations are handling more than 50 suppliers. Further there are nearly $10 \%$ AI organizations handling more than 150 suppliers which creates huge difficulty to maintain the quality and performances.

Majority of the Managers of the manufacturing sector in Sri Lanka are males $(69 \%)$ and there are only $31 \%$ female Managers in the field. According to their managerial responsibilities, they are Operations Managers (12\%), Supply Chain Managers (12\%), Inventory Control/ Warehouse Managers (12\%), Production Mangers (12\%), Transport Mangers (11\%), Procurement Managers (9\%), Logistic Managers (8\%), and Mangers of various other categories (24\%) related to the SC.

Majority of the Managers (56\%) in F\&BI are Diploma holders in their specific field and there are $42 \%$ graduates. $\mathrm{AI}$ is academically 
far better than the F\&BI, as there are $68 \%$ graduates and $24 \%$ post graduate qualified Managers.

Most of the Managers (73\%) possess more than six years overall working experience and the others also have working experience between 4-6 years.

47.1\% Managers have experience in their current position above six years and only $2 \%$ of the Managers are with less than one year experience.

Table 7.2: Results of the Mann-Whitney

\begin{tabular}{cccc}
\hline \hline $\begin{array}{c}\text { SC } \\
\text { linkages }\end{array}$ & \multicolumn{3}{c}{ Spearman's rho coefficient } \\
& F\&BI & & All \\
& $(49)$ & AI (88) & $(\mathbf{1 3 7})$ \\
Power & $0.565^{* *}$ & 0.07 & 0.123 \\
Benefits & $-0.333^{*}$ & $0.601^{* *}$ & $0.193^{*}$ \\
Risk R & $0.356^{*}$ & $0.57^{* *}$ & $0.569^{* *}$ \\
\hline \hline **. Significant at the 0.01 level. \\
*. Significant at the 0.05 level. \\
Source: Survey data
\end{tabular}

The ratings given for the four factors in the study by the Managers of these two industries were compared. Table 7.2 illustrates the results of the Mean Comparison test that compare the means of SCLs and SCP between two types of industries. Average ratings given for Benefits and SCP are significantly different in two industries. Average rating for Benefits is higher in F\&BI and the SCP ratings are higher in AI. Results of the test do not provide any statistical significance for the differences in Power and Risk Reduction.
Correlation analysis was used to test the strength and the significance of the relationships of SCL factors with the SCP of these two industries. Since the variables are not normally distributed, the spearman's Correlation Coefficient was used instead of Pearson's Correlation. The Spearman's Rank Order Correlation Coefficient is a nonparametric measure of the strength and direction of the relationship that exists between the two variables.

Table 7.3: Correlation with SCP

\begin{tabular}{lccc}
\hline \hline $\begin{array}{c}\text { SC } \\
\text { linkages }\end{array}$ & \multicolumn{3}{c}{ Spearman's rho coefficient } \\
& F\&BI & AI & All \\
& $\mathbf{( 4 9 )}$ & $\mathbf{( 8 8 )}$ & $\mathbf{( 1 3 7 )}$ \\
Power & $0.565^{* *}$ & 0.07 & 0.123 \\
Benefits & $-0.333^{*}$ & $0.601^{* *}$ & $0.193^{*}$ \\
Risk R & $0.356^{*}$ & $0.57^{* *}$ & $0.569^{* *}$ \\
\hline \hline **. Significant at the 0.01 level. \\
*. Significant at the 0.05 level. \\
Source: Survey data
\end{tabular}

According to the table 7.3, Power and Risk Reduction are demonstrating a significant positive relationships with SCP of the F\&BI. The Benefits demonstrate significant but negative relationship with SCP. In AI, Power is not showing significant relationship with SCP, but other two factors demonstrate significant positive relationships. Considering the both industries, Benefits and the Risk Reduction are the factors showing significant relationships with the SCP.

Multiple linear regression analysis was used 
to identify the significantly influential SCLs (Power, Benefits, and Risk Reduction) on the SCP of an organization. Stepwise selection method was used to select the best model for the exisitng data.

Table 7.4 illustrates the initial model fitting by using both types of manufacturing industries.

Table 7.4: Results of the Model Fitting

\begin{tabular}{lccc}
\hline \hline & $\begin{array}{c}\text { Beta } \\
\text { Std. } \\
\text { Error } \\
\left(\mathbf{R}^{2}=\mathbf{5 8 . 6} \%\right)\end{array}$ & $\begin{array}{c}\text { Stand. } \\
\text { Beta }\end{array}$ \\
$\begin{array}{l}\text { Industry type - F \&BI } \\
\text { (Constant) }\end{array}$ & 1.405 & 0.677 \\
$\begin{array}{l}\text { Risk R } \\
\text { Benefits }\end{array}$ & 0.788 & 0.122 & $0.643^{* *}$ \\
& -0.219 & 0.082 & $-0.265^{* *}$ \\
Industry type - Apparel & $\left(\mathbf{R}^{2}=\mathbf{7 4 . 3} \%\right)$ \\
(Constant) & -2.464 & 0.443 & \\
Benefits & 1.374 & 0.087 & $0.910^{* *}$ \\
Power & 0.330 & 0.048 & $0.392^{* *}$ \\
& & & \\
All & $\left(\mathbf{R}^{2}=\mathbf{4 6 . 2} \%\right)$ \\
(Constant) & -0.394 & 0.458 & \\
Risk R & 0.909 & 0.084 & $0.683^{* *}$ \\
Power & 0.185 & 0.066 & $0.176^{* *}$ \\
\hline \hline
\end{tabular}

**. Significant at the 0.01 level.

Dependent Variable: SCP

Source: Survey data

Risk and Power become the common significant influences on the SCP of the manufacturing industries, with model accuracy of $46.2 \%$. Separate multiple regression models fitted for the two industries demonstrate different behaviours of the SCLs. For F\&BI, Risk reduction shows highest influence on SCP, secondly by the Benefits with the model accuracy of
$58.6 \%$. As a behaviour, negative impact of Benefits on SCP is theoretically unrealistic. In AI, Benefits shows highest influence on SCP, Power appears as second factor with the model accuracy of $74.3 \%$.

Finally, the "type of the industry" added to the model as an independent variable, to test the moderating effect of "Type of the industry". The new model enhances the model accuracy up to $61.1 \%$, with confirming the moderating effect of the variable "Type of the industry" (table 7.5). AI demonstrates higher SCP than F\&BI, when the same level of Risk Reduction and Power apply on the SC.

variable "Type of the industry" (table 7.5). AI demonstrates higher SCP than F\&BI, when the same level of Risk Reduction and Power apply on the SC.

\section{Table 7.5: Improved Regression}

\begin{tabular}{llll}
\hline \hline & Beta & $\begin{array}{l}\text { Std. } \\
\text { Error }\end{array}$ & $\begin{array}{l}\text { Stand. } \\
\text { Beta }\end{array}$ \\
(Cons.) & -0.766 & 0.393 & \\
Risk R & 0.856 & 0.072 & $0.644^{* *}$ \\
Industry type & 0.574 & 0.079 & $0.392^{* *}$ \\
Power & 0.238 & 0.057 & $0.227^{* *}$ \\
\hline \hline **. Significant at the 0.01 level. \\
Dependent Variable: SCP \\
Source: Survey Data, sample size =138 \\
Type: 1=AI, 0= F\&BI
\end{tabular}

\section{Model}

Significance of the industry type to the model indicates that the Risk Reduction and Power influence differently on the Supply Chain Performance of the two types of industries. Risk Reduction has more impact on the SCP than the Power in manufacturing sector. 


\section{DISCUSSION}

This study has been conducted to identify the impacts of Supply chain linkages on the Supply Chain Performance. Main focus is on the Supply chain linkages construct on social relationships, instead of the technological side. The data collection was based on the Apparel and Food \& Beverages companies within BOI Zones of the Western Province. The emphasis is given to the Supply Chain Linkages and the performance within these two different industries. Zelbst et al. (2009) has conducted a similar study comparing manufacturing and service sector companies.

manufacturing and service sector companies.

The ratings given by the Managers for four factors highlight the diverse behaviour of the SC linkages in these two industries. Power in taking decisions on suppliers, buyers, and the competitors is high in F\&BI than in the AI. Benefits receive from suppliers and offer to buyers such as sharing knowledge, efficiency, innovativeness, and the quality, are higher in F\&BI than the AI. This difference is in a considerable level.

Suppliers responsiveness regarding the quality, quantity, delivery time, share information; buyers readiness to pay on time, share information knowledge, and inventory handling were considered as Risk Reduction activities. Average Risk Reduction ability is high in AI than the F\&BI. Finally, the average SCP is higher in
AI than the F\&BI and this difference is considerably high level.

All three SCLs are significantly related with SCP in the F\&BI. However, the inverse behaviour of the Benefits with SCP is unrealistic. Power is not significantly relate with SCP in AI but all three SCLs show positive relationship. As a manufacturing industry, there is a tendency to exist relationships of Benefits and Risk Reduction with their SCP. Zelbst et al. (2009) concluded that the Power, Benefits, and Risk Reduction are positively and significantly correlated with the SCP and Power has an impact on the Supply Chain relationships. Lawler (1992) and Zelbst et al. (2009) describe Power as a control related outcome of an exchange.

impact on the Supply Chain relationships. Lawler (1992) and Zelbst et al. (2009) describe Power as a control related outcome of an exchange.

The main objective of the study is to identify the impact of Supply Chain Linkages on the Supply Chain Performance. According to the regression analysis, considering two types of industries separately and together show different results.

As a manufacturing industry, Risk Reduction and Power together influence on the SCP of the organization. These two factors influence $46.2 \%$ of the variation of SCP of manufacturing industry. Zelbst et al. (2009) concluded the linkage variables Power, Benefits, and Risk reduction together 
explain $61 \%$ of the variation in Supply chain performance. However, in the current study, the Benefits have resulted with a positive but insignificant impact on the Supply chain performance.

Benefits and Power together influence on the SCP of AI and these factors control $74.3 \%$ of the SCP of AI organizations. Risk Reduction and Benefits are the influential factors for the SCP of F\&BI. 58.6\% of the change of SCP in F\&BI occurs due to the above two factors. Some of these results are not compatible with the previous research findings.

Due to the variations of the factors, influence on the SCP of these two industries, the "Type of the industry" also included to the model as an independent variable. "Type of the industry" showed significant impact on SCP with the improvement of model accuracy to 61.2\%. Selldin and Olhager (2007) also discussed variations of the SCP according the type of the product of the organization. AI shows higher level of SCP than F\&BI, when the same level of Risk Reduction and Power strategies applied.

of the industry" also included to the model as an independent variable. "Type of the industry" showed significant impact on SCP with the improvement of model accuracy to 61.2\%. Selldin and Olhager (2007) also discussed variations of the SCP according the type of the product of the organization. AI shows higher level of SCP than F\&BI, when the same level of Risk Reduction and Power strategies applied.

\section{C O N C L U S I O N S A N D RECOMMENDATIONS}

\subsection{Conclusions}

The study is conducted based on the underlying problem why the Supply chain performance differs even though the organizations enjoy the same infrastructure facilities. The study sample comprise of Apparel and Food \& Beverages companies within BOI Zones. The Zones facilitated with same labour density and ease of access for the labour market.

The study identifies the impact on Supply chain linkages on the Supply chain performance of two industry sectors, which are different from each other. The Supply chain linkages construct on Power, Benefits and Risk Reduction evaluated among Apparel and Food \& Beverages companies within Western province, Sri Lanka. The linkage variables are identified based on the social relationships within an organization's Supply Chain.

Based on the findings, the ability to control suppliers, buyers, and competitors and the ability to reduce the risk factors related to the suppliers and the buyers are the main influential factors on the Supply chain performances of the organization. These influential levels are deferent in F\&BI than in the AI. AI can achieve higher level of SCP than the F\&BI, when using the same level of Power and Risk Reduction strategies.

ability to reduce the risk factors related to the suppliers and the buyers are the main 
influential factors on the Supply chain performances of the organization. These influential levels are deferent in F\&BI than in the AI. AI can achieve higher level of SCP than the F\&BI, when using the same level of Power and Risk Reduction strategies.

AI needs to pay more attention on enhancing the two types of benefits such as benefits that will receive from the suppliers and benefits that will be offered to the buyers. Further, they have to pay attention on the power applied to the suppliers, buyers and the competitors. Higher the power applied, will result higher SCP.

F\&BI's SCP varied due to the ability of risk reduction and the level of benefits given and received. Risk reduction ability has more power to enhance the SCP of F\&BI. However, unrealistic behaviour of the influence of benefits (received and given) on SCP arise with the data.

One of the reasons to transpire this result can be the poor level of awareness regarding the advantages of benefits receiving and giving among the Managers of F\&BI.

\subsection{Recommendations}

The findings pave the way to look into the Power and Risk reduction variables, since it has a significant impact on the Supply chain performance of both industries. The Supply chain performance recognize as the ability to satisfy the ultimate customer.

The Benefits sought described in a detailed manner where suppliers and buyers Journal of Business Studies connected to the organization in a way beneficial to the organizational Supply chain performance. The top management needs to pay attention on these Benefits in developing the operational performance. Efficiencies and knowledge sharing are Benefits gained from upstream and downstream Supply Chain that is essential to increase the Supply chain performance.

The innovative ideas and novel technologies received from the buyers and suppliers create a greater influence on the organizational performance. The top management must consider the standardization of procedures between suppliers and buyers to deliver the products precisely on time to the end customers.

Further, the management involvement is needed to reduce the Risk faced by the organizations. The Supply chain linkages created on Risk reductions have a significant impact on the Supply chain performance of Sri Lankan Apparel and Food \& Beverages Industries.

Order response time and order delivery from suppliers need to be structured appropriately in order to reduce the fear of stock out at a peak demand. By sharing the market information and new ideas with the suppliers will reduce the Risk while increasing the knowledge about the market trends. 


\section{LIMITATIONS OF THE STUDY}

There are limitations to the study that should be noted. First, the generalization of the sample is questionable. The sample selected is the Apparel and Food \& Beverages companies within Sri Lankan Western province BOI zones. The respondents are only form four BOI Zones out of seven. Lack of availability of previous researches and the studies, is another limitation within Sri Lankan context. Therefore, the study is limited to a less background knowledge about the area of the study.

\section{REFERENCES}

Anderson, J., Hakansson, H., \& Johanson, J. (1994). Dyadic Business Relationships within a Business Network Context. Journal of Marketing, 58(4), 1-15.

Annual Industry Survey (AIS), (2013). Statistics and Censes Department, Sri Lanka. http://www.statistics. gov.lk/industry/ASI\%202013\%20rep ort.pdf. Last accessed 28th April 2016.

Awuah, G. (2001). A firm's competence development through its network of exchange relationships. Journal of Business \& Industrial Marketing, 16(7), 574-599.

Beamon, B. (1999). Measuring supply chain performance. International Journal of Operations \& Production Management, 19(3), 275-292.

Burke, P. (1997). An Identity Model for Network Exchange. American Sociological, 62(1), 134-150.
Chandra, C., \& Kumar, S. (2001). Enterprise architectural framework for supplychain integration. Industrial Management \& Data Systems, 101(6), 290-304.

Chua, A. (2003). Knowledge sharing: a game people play. Aslib Proceedings, 55(3), 117-129.

Cook, K., \& Whitmeyer, J. (1992). Two Approaches to Social Structure: Exchange Theory and Network Analysis. Annual Review of Sociology, 18, 109-127.

Cousins, P., Lamming, R., \& Bowen, F. (2004). The role of risk in environment-related supplier initiatives. International Journal of Operations \& Production Management, 24(6), 554-565.

Cox, A. (1999). Power, value, and supply chain management. Supply Chain Management: An International Journal, 4(4), 167-175.

Cropanzano, R., \& Mitchell, M.S. (2005). Social Exchange Theory: An Interdisciplinary Review. Journal of Management, 31(๘, 874-900.

Cucchiella, F., \& Gastaldi, M. (2006). Risk management in supply chain: a real option approach. Journal of Manufacturing Technology Management, 17(6), 700-720.

Donnell, S., \& Jing, I. (2000). Marketing standardization within global industries. International Marketing Review, 17(1), 19-33.

Farrell, M., \& Schroder, B. (1999). Power and influence in the buying centre. 
European Journal of Marketing, 33(11/12), 1161-1170.

Fawcett, S., Magnan, G., \& McCarter, M. (2008). Benefits, barriers, and bridges to effective supply chain management. Supply Chain Management: An International Journal, 13(1), 35-48.

Gakovic, A., \& Tetrick, L. (2003). Perceived organizational support and work status: a comparison of the employment relationships of part-time and full-time employees attending university classes. Journal of Organizational Behavior, 24(5), 649666.

Gliem, J., \& Gliem, R. (2003). Calculating, interpreting, and reporting Cronbach's Alpha Reliability Coefficient for Likert-Type Scales. Paper presented at the Midwest Research-to-Practice Conference in Adult, Continuing, and Community Education, The Ohio State University, Columbus, onio. 8288. http://www.ssnpstudents.com/wp/wpcontent/uploads/2015/02/GliemGliem.pdf. Last accessed 20th April 2016.

Gunasekaran, A., Patel, C., \& Tirtiroglu, E. (2001). Performance measures and metrics in a supply chain environment. International Journal of Operations \& Production Management, 21(1/2), 7187.

Habib, F., Bastl, M., \& Pilbeam, C. (2015). Strategic responses to power dominance in buyer- supplier relationships. International Journal of Physical Distribution \& Logistics
Management, 45(1/2), 182-203.

Hallen, L., \& Johanson, M. (2004). Integration of relationships and business network development in the Russian transition economy. International Marketing Review, 21(2), 158-171.

Han, B., \& Anantatmula, V. (2007). Knowledge sharing in large IT organizations: a case study. VINE, 37(4), 421-439.

Handfield, R., \& Nichols, E. (2002). Supply Chain Redesign: Transforming Supply Chains into Integrated Value Systems. New Jersey, USA: F T Press.

Hoejmose, S., Grosvold, J., \& Millington, A. (2013). Socially responsible supply chains: power asymmetries and joint dependence. Supply Chain Management: An International Journal, 18(3), 277-291.

Jantunen, A. (2005). Knowledge-processing capabilities and innovative performance: an empirical study. European Journal of Innovation Management, 8(3), 336-349.

Krajewski, L., Ritzman, L., Malhotra, M., \& Srivastava, S. (2011). Operations Management: Processes and Supply Chains. (9th ed.). New Delhi, India: Pearson Education India.

Lawler, E. (1992). Affective Attachments to Nested Groups: A Choice-Process Theory. American Sociological Review, 57(3), 327-339.

Lee, C., Kwon, I., \& Severance, D. (2007). Relationship between supply chain performance and degree of linkage 
among supplier, internal integration, and customer. Supply Chain Management: An International Journal, 12(6), 444-452.

Lee, H., \& Billington, C. (1995). The Evolution of Supply-ChainManagement Models and Practice at Hewlett-Packard. Interfaces, 25(5), 42-63.

Lee, Y., Cheng, F., \& Leung, Y. (2009). A quantitative view on how RFID can improve inventory management in a supply chain. International Journal of Logistics: Research and Applications, 12(1), 23-43.

Lin, H. (2007). Knowledge sharing and firm innovation capability: an empirical study. International Journal of Manpower, 28(3/4), 315-332.

Lockamy III, A., \& McCormack, K. (2012). Modeling supplier risks using Bayesian networks. Industrial Management \& Data Systems, 112(2), 313-333.

Magretta, J. (1998). The Power of Virtual Integration: An Interview with Dell Computer's Michael Dell. Harvard Business Review, 76(2), 73-84.

Markovsky, B., Skvoretz, J., Willer, D., Lovaglia, M., \& Erger, J. (1993). The Seeds of Weak Power: An Extension of Network Exchange Theory. American Sociological Review, 58(2), 197-209.

Matook, S., Lasch, R., \& Tamaschke, R. (2009). Supplier development with benchmarking as part of a comprehensive supplier risk management framework. International Journal of Operations
\& Production Management, 29(3), 241-267.

Neill, B., \& Adya, M. (2007). Knowledge sharing and the psychological contract. Journal Of Managerial Psychology, 22(4), 411-436.

Nunnally, J., \& Bernstein, I. (1994). Psychometric theory, Issue 972. $\left(3^{\text {rd }}\right.$ ed.). New York: McGraw-Hill.

Okongwu, U., Brulhart, F., \& Moncef, B. (2015). Causal linkages between supply chain management practices and performance. Journal of Manufacturing Technology Management, 26(5), 678-702.

Olkkonen, R., Tikkanen, H., \& Alajoutsijarvi, K. (2000). The role of communication in business relationships and networks. Management Decision, 38(6), 403409.

Pels, J. (1999). Exchange relationships in consumer markets?. European Journal OfMarketing, 33(1/2), 19-37.

Perry, M., \& Sohal, A. (2001). Effective quick response practices in a supply chain partnership - An Australian case study. International Journal of Operations \& Production Management, 21(5/6), 840-854.

Rungtusanatham, M., Salvador, F., Forza, C., \& Choi, T. (2003). Supply-chain linkages and operational performance. International Journal of Operations \& Production Management, 23(9), 10841099.

Sahay, B. (2003). Understanding trust in supply chain relationships. Industrial Management \& Data Systems, 103(8), 553-563. 
Salvador, F., Forza, C., Rungtusanatham, M., \& Choi, T. (2001). Supply chain interactions and time-related performances. International Journal Of Operations \& Production Management, 21(4), 461-475.

Selldin, E., \& Olhager, J. (2007). Linking products with supply chains: testing Fisher's model. Supply Chain Management: An International Journal, 12(1), 42-51.

Shah, J. (2009). Supply Chain Management: Text and Cases. New Delhi, India: Pearson Education India.

Shore, L., Bommer, W., Rao, A., \& Seo, J. (2009). Social and economic exchange in the employee-organization relationship: the moderating role of reciprocation wariness. Journal of Managerial Psychology, 24(8), 701721.

Singh, P., \& Power, D. (2009). The nature and effectiveness of collaboration between firms, their customers and suppliers: a supply chain perspective. Supply Chain Management: An International Journal, 14(3), 189-200.

Sorensen, H. (2009). Why competitors matter for market orientation. European Journal of Marketing, 43(5/6), 735-761.

Tohidinia, Z., \& Mosakhani, M. (2010). Knowledge sharing behaviour and its predictors. Industrial Management \& Data Systems, 110(4), 611-631.

Vilko, J., Ritala, P., \& Edelmann, J. (2014). On uncertainty in supply chain risk management. The International Journal of Logistics Management, 25(1) 3-19
Walker, H., Thye, S., Simpsom, B., Lovaglia, M., Willer, D., \& Markovsky, B. (2000). Network Exchange Theory: Recent Developments and New Directions. Social Psychology Quarterly, 63(4), 324-337.

Wang, D., Tsui, A., Zhang, Y., \& Ma, L. (2003). Employment relationships and ? $\mathrm{rm}$ performance: evidence from an emerging economy. Journal of Organizational Behavior, 24, 511-535.

Whitten, G., Green, K., \& Zelbst, P. (2012). Triple-A supply chain performance. International Journal Of Operations \& Production Management, 32(1), 2848.

Zelbst, P., Green, K., Sower, V., \& Reyes, P. (2009). Impact of supply chain linkages on supply chain performance. Industrial Management \& Data Systems, 109(5), 665-682.

Zineldin, M., \& Jonsson, P. (2000). An examination of the main factors affecting trust/commitment in supplier-dealer relationships: an empirical study of the Swedish wood industry. The TQM Magazine, 12(4), 245-266.

Zong, D. (2008). Supply chain transformation by ERP for enhancing performance: An empirical investigation. Advances in Competitiveness Research, 16(1), 8798. 